\title{
Definición de la situación de los menores desvinculados de los grupos armados ilegales en los actos jurídicos y sus efectos psicoeducativos ${ }^{*}$
}

\author{
Definition of the Situation of Children Demobilized Illegal Armed Groups \\ in the Legal Acts and Psychoeducational Effects \\ Definição da situação dos menores de idade desvinculados dos grupos \\ armados ilegais nos atos jurídicos e seus efeitos psicoeducativos
}

\author{
Jaime Alberto Carmona Parra ${ }^{\star *}$ \\ Universidad Católica de Manizales
}

FeCHA DE RECEPCIÓN: 30 DE SEPTIEMBRE DE 2013 • FECHA DE ACEPTACIÓN: 5 DE MAYO DE 2014

Doi: dx.doi.org/10.12804/esj16.02.2014.05

Para citar este artículo: Carmona P., J. A. (2014). Definición de la situación de los menores desvinculados de los grupos armados ilegales en los actos jurídicos y sus efectos psicoeducativos. Estudios Socio-Jurídicos, 16(2), 163-177. Doi: dx.doi. org/10.12804/esj16.02.2014.05

\section{RESUMEN}

El artículo inicia con una reflexión sobre los enunciados performativos, que constituyen actos de habla, para mostrar que el derecho contribuye a la creación de realidad y de subjetividad. Con base en este argumento, se examinan cinco definiciones de la situación de los menores desvinculados de los grupos armados ilegales en Colombia, denominadas de acuerdo con sus efectos psicoeducativos: victimizante, patologizante, criminalizante, idealizante y responsabilizante. Cada definición se examina en función de su filiación filosófica, determinista, indeterminista o interaccionista; en sus efectos en la construcción de la identidad de los menores y en su apelación a la imputabilidad o inimputabilidad jurídica. Al final del artículo se muestran las propuestas de intervención que se derivan de cada una de las definiciones y se muestra el papel que puede jugar la justicia restaurativa en la construcción de un mo-

* Artículo producto de la ponencia presentada en el V Congreso Internacional Derecho y Sociedad por un Pensamiento Latinoamericano, realizado los días 22, 23 y 24 de agosto de 2013, en la ciudad de Manizales.

** Doctor en Psicología Social de la Universidad Complutense de Madrid; magíster en Ciencias Sociales de la Universidad de Antioquia y magíster en Educación de la Universidad Católica de Manizales. Docente asociado de la Maestría en Educación de la Universidad Católica de Manizales; autor de múltiples libros y artículos científicos. Cra. 23 \# 60-63 Manizales (Caldas, Colombia). Correo electrónico: jacarmona@ucm.edu.co 
delo de atención responsabilizante para los menores desvinculados de los grupos armados ilegales y otras víctimas del conflicto armado, que les garantice la restitución de los derechos y a la vez los empodere como actores protagónicos en la redefinición de su rol social y la reconstrucción de su identidad.

Palabras clave: actos jurídicos, definición de la situación, efectos psicoeducativos, niños.

\section{ABSTRACT}

The article begins with a reflection on performative utterances, which are speech acts, to show that the right contributes to the creation of reality and subjectivity. Based on this argument examines five definitions of the situation of children demobilized from illegal armed groups in Colombia, named according to their effects psychoeducational: victimizing, pathologizing, criminalizing, idealizing and responsabilizing. Each definition is examined in terms of their philosophical affiliation, deterministic, nondeterministic or interactionist, its effects on the construction of the identity of minors and in his appeal to responsibility and legal insanity. At the end of the article shows the intervention proposals arising from each of the definitions and shows the role that restorative justice can play in building a model of care which confers responsibility to the children demobilized from illegal armed groups, and other victims of armed conflict, which guarantees the restitution of rights and also empowers them as key actors in redefining their social role and identity reconstruction.

Key words: acts, definition of the situation, psychoeducational effects, children.

\section{RESUMO}

O artigo inicia com una reflexão sobre os enunciados performativos, que constituem atos de fala, para mostrar que o direito contribui à criação de realidade e de subjetividade. Com base neste argumento examinam-se cinco definições da situação dos menores de idade desvinculados dos grupos armados ilegais na Colômbia, denominadas de acordo com seus efeitos psicoeducativos: vitimizante, patologizante, criminalizante, idealizante e responsabilizante. Cada definição examina-se em função de sua filiação filosófica, determinista, indeterminista ou interacionista; seus efeitos na construção da identidade dos menores de idade e um sua apelação à imputabilidade ou inimputabilidade jurídica. Ao final do artigo se mostram as propostas de intervenção que se derivam de cada uma das definições e se mostra o papel da justiça restaurativa na construção de um modelo de atenção responsabilizante, para os menores de idade desvinculados dos grupos armados ilegais, e outras vítimas do conflito armado, que lhes garante a restituição dos direitos e ao mesmo tempo os empodere como protagonistas na redefinição de seu rol social e a reconstrução de sua identidade.

Palavras-chave: Atos jurídicos, definição da situação, efeitos psicoeducativos, crianças. 
El filósofo John Langshaw Austin en su 'teoría de los actos de habla' propone la categoría de 'enunciados performativos' (Austin, 1982, p. 12). Se refiere a aquellos casos en que una acción se realiza por medio de un acto de habla. Un ejemplo que menciona el autor es la promesa. Cuando alguien dice "Yo prometo", en el mismo momento en que pronuncia la frase se compromete. Otra frase como "Yo te bautizo" es, también, un ejemplo claro. El derecho es, por excelencia, un campo de enunciados performativos que no solamente producen efectos en la realidad, sino que contribuyen a la creación de nuevas realidades. Una frase como "El acusado es declarado culpable" tiene el efecto de cambiar el rol social de ciudadano a delincuente y con ello el destino de un ser humano. Un acto jurídico como la creación de una ley implica una transformación de las coordenadas mismas que constituyen la realidad que habitamos los humanos. Un ejemplo más simple es el de la poligamia, que, según el contexto jurídico, es un delito o un derecho. Constataciones de esta clase llevan a Dager Aguilar a proponer:

Todos los elementos que componen el control social se encuentran implicados en la materialización de las definiciones del delito, del delincuente y la delincuencia; en tal sentido, definirá cuáles conductas serán tipificadas como delito, razón por la cual crea al delito al tener que definirlo (nivel legislativo), quién es delincuente, creando precisamente a ese delincuente al identificar a una persona en vez de a otra que ha realizado una conducta similar (nivel policial-judicial) y cuál es la delincuencia (Aguilar, 2013).

Esta afirmación tiene un telón de fondo mucho más radical, a saber, que la ley no solamente tiene su lugar en la definición del delito y del delincuente, sino también de la paternidad y los padres, de las profesiones y los profesionales, es decir, en las definiciones que establecen los roles de los actores sociales. Cuando en un acto de graduación se dice: "La república de Colombia y en su nombre la universidad X concede el título de...", se está queriendo decir que es la ley la que permite la existencia de una profesión y sus profesionales. Nadie puede ser profesional por fuera de las profesiones definidas por la ley. La realidad social que habitamos los humanos tiene un fundamento legal. La ley es una fuente de creación de realidad.

Este hecho fundamental de la realidad humana se conoce en el campo de las ciencias sociales como el 'teorema de Thomas'. Fue formulado 
por el sociólogo norteamericano William Thomas en 1923: "If men define situations as real, they are real in their consequences" (Thomas, 1928, p. 99) ("Si los seres humanos definen situaciones como reales, ellas son reales en sus consecuencias"). Este teorema también es llamado por autores como Berger y Luckman como la 'definición de la situación' (Berger y Luckmann, 1968, p. 196). Si volvemos sobre la cita de Aguilar, podemos constatar que el autor concibe la actividad de legislar como una praxis en la que se define una situación: 'el delito', que implica la definición de un rol social: 'delincuente', y una problemática: 'la delincuencia'.

Ciertamente, hay múltiples discursos tributarios de la praxis de definir situaciones: la ciencia, la filosofía, la religión, incluso el sentido común de cada complejo cultural. Sin embargo, es el discurso jurídico el que confiere un nivel de objetivación y estabilidad mayor, hasta el punto de volver obligatorio su cumplimiento y establecer graves sanciones a quienes se separen de dichas definiciones.

La investigación con víctimas del conflicto armado en diferentes lugares del mundo nos muestra los efectos psicoeducativos de las acciones jurídicas. En la investigación titulada La carrera de las niñas soldado en Colombia (Carmona, 2009), el autor muestra cinco definiciones de la situación de los menores desvinculados de los grupos armados ilegales y examina los efectos de estas en la reconstrucción de su identidad y en el posicionamiento que como actores sociales tendrán una vez se reinserten a la vida civil.

Las cinco definiciones propuestas por el autor son: victimizante, patologizante, criminalizante, idealizante y responsabilizante. Cada una de ellas tiene en su base unas implicaciones ontológicas, epistemológicas y jurídicas, unas consecuencias identitarias y éticas, y unos intereses políticos. Veamos cada una de ellas:

\section{Definición victimizante}

Muestra al menor que se vincula a los grupos armados exclusivamente como víctima. Acentúa la inimputablidad desde el punto de vista jurídico. Es la más generalizada en el campo de las ciencias sociales y, de alguna 
manera, era la que prevalecía en la legislación colombiana hasta el año 2006. Veamos dos ejemplos: "Muchos niños, niñas y jóvenes no tienen más alternativas que ingresar a un grupo armado... es claro que en Colombia no existe tal cosa como reclutamiento voluntario" (Coalición contra la vinculación de niños, niñas y jóvenes al conflicto armado en Colombia, 2003, p. 88); y "No hay voluntariedad en la participación del conflicto armado simplemente porque no hay posibilidad de escogencia" (Bello y Ruiz, 2002, p. 23).

Esta definición acentúa la dimensión del menor vinculado a los grupos armados ilegales como un sujeto jurídicamente inimputable. Ontológicamente parte de una concepción eminentemente determinista unicausal o multicausal y pone el énfasis explicativo en factores externos, como el Estado, la comunidad y la familia. La consecuencia identitaria fundamental es la des-responsabilización de los menores frente a sus acciones. Este efecto se deriva de confundir la categoría jurídica de imputabilidad con el concepto psicoeducativo de responsabilidad.

Veamos un testimonio de la directora de un programa de retorno a la vida civil de menores desvinculados del conflicto armado sobre los efectos identitarios de esta definición victimizante. Según ella, los menores llegan al programa en una actitud generalmente modesta, reflexiva, incluso autocrítica respecto de su participación en los grupos armados, pero muy rápidamente hacen una lectura de contexto y asumen un posicionamiento de acuerdo con la lectura que hacen de la definición de su situación para sacarle el mejor provecho:

Es supremamente difícil trabajar y jugar con ellos, porque a veces es como el merecimiento de todo pero sin hacer el esfuerzo para poder lograr conseguir lo que quiero. Fuera de eso también a veces ellos se paran en la posición de ser héroes de guerra (...) están como en la posición de "denme que yo recibo", y "yo soy el menor garante de derechos, el héroe de guerra, que el gobierno y el Estado colombiano me prometieron no sé qué y me lo tienen que dar". Entonces es el individuo que no da puntada sin dedal y que espera cualquier momento para que uno le retribuya y que uno le dé todo lo que él está pidiendo (...) una demanda constante pero limitado desde su responsabilidad y desde lo que él puede dar también (Carmona, Moreno y Tobón, 2012, p. 55). 


\section{Definición patologizante}

Muestra al menor que se vincula a los grupos armados ilegales como un desadaptado o un sujeto traumatizado. También apela a la inimputabilidad jurídica. Por su misma definición, tiene sus exponentes en el campo de los profesionales del campo de la salud mental. Explica la vinculación de los menores a los grupos armados ilegales como producto de desajustes comportamentales, trastornos disociales del comportamiento, identificaciones inconscientes con actores armados o crisis propias de la adolescencia.

Veamos dos argumentos patologizantes que explican la vinculación de los niños a los grupos armados ilegales en Colombia: "Son aquellos que deciden tomar la ruta del acto franqueando la fantasía ligada a actos violentos y a la destrucción, lo cual implica realizar elecciones por la vía que contiene la lucha cuerpo a cuerpo con el otro, arma a arma, muerte a muerte" (Bello et al., 2003, p. 93); otro argumento de inspiración psicoanalítica a propósito del debate sobre la voluntariedad o la obligatoriedad de la vinculación de los niños: "Nada es más forzado que un enganche inconsciente" (Castro, 2006).

Esta definición patologizante de la situación parte de una premisa ontológica y epistemológica unicausal determinista, pero, a diferencia de la definición victimizante, en este caso la causalidad no es remitida a factores externos, sino subjetivos. También en este caso hay un efecto de desresponsabilización radical. Los efectos identitarios pueden ser altamente problemáticos. Si el menor desvinculado se asume a sí mismo como un desadaptado o como enfermo, esto podría generar efectos incapacitantes para sus interacciones en la vida civil.

En su texto Infancia y guerra en Centroamérica, el investigador Florentino Moreno nos ofrece un relato particularmente valioso para mostrar estos efectos de formación de identidad que se pueden apoyar en una resignificación de acontecimientos a la luz de una visión particular:

Estábamos reunidos un grupo de personas que habíamos estado en distintas guerras atendiendo y trabajando con niños. Una escena se me quedó grabada y la cuento muchas veces porque tiene mucho que ver con lo que voy a decir después a propósito de la intervención. El primer día, cuando nos reunieron a la gente que veníamos de Israel o Palestina, llegó 
un niño del sureste asiático que nos contó su historia en un inglés perfecto. Había sido adoptado por un matrimonio norteamericano. Una historia terrible. Luego terminó su historia con lágrimas en los ojos y tocando una música típica con la flauta. Todo el mundo lloró con la terrible historia del niño, claro. Al día siguiente, en el hotel, encendí la televisión y estaba el mismo niño contando la misma historia y al final lloraba nuevamente, tocaba la flauta, lloraba y se le entrecortaba la voz. Por la tarde cuando se inauguró el congreso, este niño expuso lo mismo. Hizo exactamente igual: cuando terminó de hablar, otra vez lloró y otra vez tocó la música. Este niño tenía 22 años y llevaba aproximadamente 9 o 10 años viviendo en EE. UU. ¿Qué es lo que sucedía con este muchacho? Sin mala intención, desde luego, y con todo el amor del mundo, los padres adoptivos le habían convertido en un profesional del trauma (Moreno, 1991, p. 122).

\section{Definición criminalizante}

Muestra al menor de edad que se vincula a los grupos armados ilegales como un delincuente juvenil, al cual solo un asunto cronológico lo diferencia del criminal adulto que llegará a ser. Desde el punto de vista jurídico, acentúa la imputabilidad. Es la definición que se materializó en la Ley 1098 de 2006. Veamos un argumento a favor de ella: "Este rechazo a la responsabilidad penal de los adolescentes es un rechazo a la responsabilidad a secas. No puede ser que la condición de adolescente se transforme en América Latina en una patente de corso [sic]" (García, 2003, p. 76).

Esta definición muestra una filiación radicalmente indeterminista, en la medida en que pone el acento de la explicación en la libre autodeterminación. Los efectos de esta definición son los más graves. Desde el punto de vista social, tiene la indeseable consecuencia de las explicaciones tautológicas que explican las problemáticas por los actores sociales que las agencian. Por ejemplo, las que explican la guerrilla como un problema causado por los guerrilleros, el narcotráfico por los narcotraficantes, la drogadicción por los drogadictos y la prostitución por las prostitutas. Estas explicaciones tautológicas son la base de visiones esencialistas de los fenómenos, legitiman la estigmatización y justifican la ideología de la 'defensa social' que en algunos casos es tomada como coartada por los llamados grupos de 'limpieza social'. 
Ángela Sobrino, investigadora española del fenómeno de vinculación de menores a grupos armados ilegales, advierte la necesidad de trabajar sobre los efectos sociales estigmatizantes de esta definición esencialista criminalizante: "Es necesario ofrecer a la comunidad programas de entrenamiento para que los líderes locales, profesores, padres y religiosos, entiendan y acepten a los niños soldado desmovilizados" (Sabrino, 2001, p. 54).

\section{Definición idealizante}

Muestra al menor que se vincula a los grupos armados ilegales como un luchador juvenil, que a su temprana edad ya tiene una conciencia social que lo lleva a luchar por una causa política. Desde el punto de vista jurídico, esta definición se sitúa en el debate entre la criminalización por parte de los que defienden el statu quo y la apelación al derecho de los pueblos a la rebelión contra la tiranía, por parte de aquellos que exaltan la participación de los adolescentes en las luchas político-militares de sus pueblos. También acentúa una concepción indeterminista del púber y el adolescente, que fue muy difundida en Latinoamérica en los años setenta y ochenta del siglo XX, pero que actualmente en Colombia, por la degradación y deslegitimación que ha sufrido la rebelión armada, puede sonar bastante extraña. Un ejemplo paradigmático de esta definición lo encontramos en el texto Niñez y guerra en Centroamérica del investigador español Florentino Moreno:

El caso más emblemático es el de la niña Brenda Rocha, que en 1983 perdió uno de sus brazos cuando tenía 15 años. En una concentración muy importante, en la que estaba presente la plana mayor de los sandinistas, la niña se dirigió a la multitud... "He perdido un brazo y estoy dispuesta a dar el otro por la revolución". Los carteles que se editaron con su imagen se distribuyeron por todo el país con una frase que quedó asociada a su nombre: "La sonrisa de Nicaragua" (Moreno, 1991, p. 30).

En la investigación titulada Mujeres no contadas, que analiza la experiencia de un grupo de mujeres excombatientes de diferentes grupos guerrilleros colombianos, militantes en las décadas de los setenta y los ochenta (algunas de las cuales iniciaron su militancia siendo menores de edad), 
encontramos otro valioso testimonio: "Incluso para aquellas mujeres que expresaron haberse sentido más atraídas por lo militar que por lo político, o para aquellas que tuvieron una formación política menor, sus experiencias en la participación en los grupos insurgentes tuvo un sentido político: la transformación de las condiciones sociales de injusticia e inequidad" (Londoño y Nieto, 2006, p. 157).

Y, a continuación, aportan un testimonio de una excombatiente: "Yo ingresé a la guerrilla a muy corta edad, todo por una razón social, y hasta ahorita creo que no hemos hecho nada incorrecto" (Londoño et al., 2006, p. 55).

Algo semejante podemos encontrar en las respuestas que ofrecían los comandantes guerrilleros salvadoreños del grupo Farabundo Martí para la Liberación Nacional (FMLN) ante la pregunta por la vinculación de niños en la guerrilla:

La razón es muy sencilla, porque ESO, es lo que ellos quieren hacer. Los niños quieren que acabe la guerra y quieren que cuanto antes los soldados desaparezcan de su vida. Saben la importancia que tiene su colaboración para que esto sea una realidad, porque ven el resultado de su participación y eso les anima a seguir viviendo y colaborando más, aun a sabiendas de que arriesgan sus vidas. Es algo que han ido entendiendo por ellos mismos, por la dolorosa cotidianidad que han enfrentado por tanto tiempo (Moreno, 1991, p. 200).

Veamos la visión de dos psicólogas nicaragüenses, también citadas por Moreno: "Sin embargo, el niño, a pesar de su propia naturaleza, supo interpretar su mundo, identificó a su enemigo y se integró a la lucha del pueblo" (Moreno, 1991, p. 28).

Los efectos psicoeducativos de esta definición idealizante en la identidad de los menores vinculados a grupos armados ilegales dependen del desenlace del conflicto; en el caso nicaragüense, el triunfo de la Revolución Sandinista en su momento los elevó a la condición de héroes; en el caso de los conflictos armados que no han tenido igual desenlace, el paso de la idealización a la criminalización suele ser lo más habitual. El indeterminismo radical que está en la base de esta definición del menor combatiente conlleva una hiper-responsabilización que, además de servir a la exaltación 
o imputación, facilita escamotear la responsabilidad de todos los demás actores sociales en el fenómeno: los grupos armados legales e ilegales que usan a los niños como instrumentos de guerra, las familias y las comunidades expulsoras que facilitan el reclutamiento de los grupos, y, principalmente, el Estado que les niega sus derechos y no propicia oportunidades y horizontes de realización que funcionen como elementos protectores frente al riesgo de la vinculación.

\section{Definición responsabilizante}

La reflexión precedente nos permite introducir el tema de la justicia restaurativa y sus efectos psicoeducativos para los menores vinculados a los grupos armados, que son las primeras víctimas del conflicto.

La justicia restaurativa o justicia reparadora es un movimiento social y una teoría con carácter internacional que propone una redefinición de la justicia penal. Esta perspectiva concibe el crimen o delito ante todo como un daño en contra de una persona concreta y de los vínculos interpersonales, a diferencia de la justicia penal tradicional que tiene un carácter retributivo y propone que el delito es una transgresión de una norma jurídica, en donde el afectado principal es el Estado.

En la justicia restaurativa, la víctima desempeña un rol protagónico en el proceso judicial y puede beneficiarse de una forma de restitución o reparación a cargo del responsable o autor del delito. En esta perspectiva, se usa la categoría 'ofensor' como concepto alternativo al de 'delincuente', pues la justicia restaurativa evita la estigmatización de la persona que ha incurrido en un delito (Blanco, Díaz, Heskia y Rojas, 2004, pp. 29-39).

A diferencia de la justicia tradicional, en la que la infracción a la norma y el castigo constituyen el eje central, la justicia restaurativa pone el foco en las consecuencias del delito para una persona concreta y la necesidad de reparar. Busca que el ofensor se responsabilice de las consecuencias de su acción, procurando que en el encuentro con la víctima haya una reconciliación basada en la restitución del daño y el perdón; busca también que se restituya el lazo social, procurando la reintegración del transgresor en la comunidad, con lo cual se fortalece el sentimiento de seguridad quebrantado. 
La justicia restaurativa crea el escenario para otra definición de la situación de los menores vinculados a grupos armados ilegales que podemos denominar como responsabilizante. Pero no se trata de la visión de la responsabilidad de la justicia tradicional en la que equivale a imputabilidad y que conduce a la criminalización.

Se trata de una responsabilización que tiene como finalidad psicoeducativa la asunción de una posición ética por parte del ofensor, la cual permite evitar los efectos identitarios des-responsabilizantes de las visiones deterministas y los criminalizantes de las visiones indeterministas.

Esta definición responsabilizante del menor vinculado a los grupos armados ilegales lo muestra como un actor social, a la vez determinado y determinante, es decir, un agente social activo, capaz de transformar la realidad y transformarse a sí mismo, capaz de hacerse cargo de las consecuencias de sus acciones y de empoderarse de una manera protagónica de su propio proceso de reinserción a la sociedad.

Un ejemplo especialmente ilustrativo de los efectos psicoeducativos de la justicia restaurativa en menores de edad vinculados a pandillas lo socializó la hermana Alba Stella Barreto -Fundación Paz y Bien, del distrito de Agua Blanca en la ciudad de Cali-, en el evento Preparémonos para la Paz, organizado por la Secretaría de Equidad y Género de la Gobernación de Antioquia (Barreto, 2013).

La Hermana relató una experiencia en el distrito de Agua Blanca en Cali, que, por lo sencilla y cotidiana, es mucho más significativa para mostrar en los alcances de este enfoque en cuanto a los efectos psicoeducativos cuando se ha convertido en una cultura que brinda a una comunidad unos medios alternativos para resolver los conflictos sociales que se derivan de la violación de la ley. ${ }^{1}$

En el barrio en el que la Hermana tiene su trabajo, desde hace varios años se ha venido implementando el modelo de la justicia restaurativa y una parte de la comunidad ya se ha empoderado de este modelo para la resolución de sus conflictos.

1 Diana Britto, en su libro Justicia restaurativa: reflexiones sobre la experiencia de Colombia (Britto, 2010), hace un estudio de las Comunidades de Paz de Agua Blanca. Los manuales de formación de justicia restaurativa de la Escuela Rodrigo Lara Bonilla brindan un panorama importante sobre este enfoque. Otras valiosas experiencias son la de Hogares Claret en Piedecuesta (Santander) y la Asociación Cristiana de Jóvenes en Bogotá. 
La Hermana refiere que hace algunos meses dos chicos del barrio que pertenecen a una banda criminal entraron a su oficina, la amenazaron con armas blancas y le robaron dos celulares nuevos que había adquirido recientemente la institución. Pocos días después, la llamaron y le dijeron que querían hablar con ella, porque querían 'reparar' (el gesto y el uso de la expresión muestra que los chicos ya tienen interiorizado el modelo). La citaron en un lugar el siguiente lunes a las 9 de la mañana. La monja aceptó la cita. Efectivamente, a la hora fijada se encontraron y acordaron cómo reparar. En la institución estaban ampliando la construcción y necesitaban mano de obra. El acuerdo fue que ellos trabajarían en la obra y la mitad del dinero de su remuneración semanal se les entregaría, la otra mitad se abonaría a la 'reparación' hasta que pagaran el valor de los dos celulares. La hermana comenta que estos dos chicos en este momento son sus amigos, la cuidan y cada tanto van a visitarla y a tomar café con ella.

Esta nueva definición responsabilizante de la situación del menor vinculado a grupos armados ilegales $y$, en general, para el menor infractor de la ley penal, tiene una filiación filosófica interaccionista que le permite resolver la dicotomía entre las visiones deterministas e indeterministas, lo cual ayuda a construir una nueva visión de la responsabilidad más allá de la antinomia de la imputabilidad y la inimputabilidad penal. En esta nueva visión, la responsabilidad no equivale a la imputabilidad y la inimputabilidad no se confunde con la des-responsabilización. Esta visión interaccionista del comportamiento humano tiene la ventaja de mantener simultáneamente la atención sobre el contexto y el actor social sin incurrir en la tentación de explicar un hecho solamente por las circunstancias o solamente por el actor.

Pero este es solo uno de los efectos psicoeducativos de las acciones jurídicas desde la justicia restaurativa en un actor social particular que con frecuencia aparece en la doble condición de víctima y victimario.

Sin duda, uno de los efectos psicoeducativos más importantes está en relación con otras víctimas que no son victimarias: las madres de desaparecidos, las mujeres violadas, los desplazados, los despojados de sus tierras. El lugar marginal que les otorga la justicia tradicional a estos actores sociales tiene el efecto de revictimizarlos, con la marginación que, en últimas, deriva también en estigmatización y exclusión social radical. Esta situación de humillados y ofendidos que queda irresuelta se convierte en una bomba 
de tiempo social que tarde o temprano desata sus efectos destructivos sobre la sociedad.

La justicia restaurativa y las acciones jurídicas que se inspiran en este enfoque y le otorgan un lugar protagónico a las víctimas en el proceso de reparación tienen un poderoso impacto psicoeducativo en estas y en sus comunidades, en la medida en que les restituyen su dignidad y, desde su condición, les permiten construir redes sociales y tejidos simbólicos con otras víctimas.

\section{Conclusiones}

Las definiciones victimizante y patologizante de los menores desvinculados de los grupos armados ilegales, y, en general, de los infractores de la ley penal, son filosófica y ontológicamente deterministas, apelan a la inimputabilidad de los menores y tienen unos efectos psicoeducativos des-responsabilizantes. Las definiciones criminalizante e idealizante son ontológicamente indeterministas, tienen un efecto psicoeducativo hiperresponsabilizante que acentúa la imputabilidad y con ella la estigmatización. La definición responsabilizante es filosófica y ontológicamente interaccionista, favorece el empoderamiento del proceso de retorno a la vida civil, la asunción de una posición ética y de la reconstrucción de la identidad por parte de los menores desvinculados de los grupos armados ilegales y, en general, de aquellos en conflicto con la ley penal.

De cada una de estas cinco definiciones, se deriva de manera lógica una propuesta de intervención. Si el menor en conflicto con la ley penal es visto como una víctima (definición victimizante), la acción consecuente es protegerlo. Los proyectos inspirados en esta definición tendrán un carácter de programas de protección; en este caso, se asimila su situación y su tratamiento al de los niños en situación de calle. Si es visto como un enfermo (definición patologizante), la acción consecuente es brindarle un tratamiento; en este caso, se asimilan a los drogodependientes y los programas de retorno a la vida civil se asemejan a las comunidades terapéuticas. Si es visto como un delincuente juvenil (definición criminalizante), la estrategia será la defensa social, la disminución de la edad para imponerles medidas más drásticas. Si es visto como un luchador juvenil (definición idealizante), 
lo lógico será la exaltación de su gesto, como lo hicieron los movimientos revolucionarios centroamericanos en su momento. Si la definición es la del niño capaz de empoderarse de su historia y de su rol social (definición responsabilizante), la estrategia será restituirle sus derechos y comprometerlo como sujeto ético a que devenga un actor social protagónico su proceso de retorno a la vida civil.

\section{Referencias}

Aguilar, D. (2013). Fundamentos generales sobre criminología y control social. Recuperado de www.eumed.net/rev/cccss/08/daa10.htm

Austin, J. (1982). Cómo hacer cosas con palabras. Barcelona: Paidós.

Barreto, A. E. (mayo, 2013). Experiencia de justicia restaurativa en el distrito de Agua Blanca. Ponencia presentada en Preparémonos para la Paz, Gobernación de Antioquia, Medellín.

Bello, M., G Ruiz, S. (2003). Conflicto armado, niñez y juventud: una perspectiva psicosocial. Bogotá: Universidad Nacional de Colombia, Fundación Dos Mundos.

Berger, P., E Luckmann, T. (1968). La construcción social de la realidad. Buenos Aires: Amorrortu.

Blanco, R., Díaz, A., Heskia, J., E Rojas, H. (2004). Justicia restaurativa: marco teórico, experiencias comparadas y propuestas de politica pública. Santiago de Chile: Universidad Alberto Hurtado

Britto, D. (2010). Justicia restaurativa: reflexiones sobre la experiencia en Colombia. Loja: Universidad Técnica Particular de Loja.

Carmona, J. (2009). La carrera de las niñas soldado en Colombia: un estudio desde el punto de vista del agente (Tesis doctoral, Universidad Complutense de Madrid, España).

Carmona, J., Moreno, F., \& Tobón, J. (2012). La carrera de las niñas en los grupos guerrilleros y paramilitares de Colombia: un estudio desde el punto de vista del agente. Medellín: Funlam.

Castro, M. (julio, 2006). El asunto de la guerra cuando se trata de los más jóvenes. Ponencia presentada en el IV Encuentro Nacional de Red de Investigadores: Niñez y Conflicto Armado, Medellín.

Coalición contra la Vinculación de Niños, Niñas y Jóvenes al Conflicto Armado en Colombia. (2003). La situación de niños, niñas y jóvenes en el marco del conflicto armado en Medellin. Medellín: Coalición. 
García, E. (2003). Niñez y conflicto armado. Bogotá: Universidad de los Andes.

Londoño, L., \& Nieto, Y. (2006). Mujeres no contadas: proceso de desmovilización y retorno a la vida civil de mujeres excombatientes en Colombia 1990-2003. Medellín: La Carreta Social.

Moreno, F. (1991). Infancia y guerra en Centroamérica. San José: Flacso.

Sabrino, Á. (2001). Desencadenantes de los conflictos armados. Participación de los niños en las guerras. En J. Fernández, F. Miralles, \& B. Gonzáles, Adiós a las armas: ni un solo niño más en las guerras (p. 201). Madrid: Pontificia Universidad de Comillas.

Thomas, W. (1928). The child in America: behavior problems and programs. New York: Alfred A. Knopf. 
